asked why 120 certified lunatics were kept in the workhouse ; and he received the old stereotyped answer, that there was no room in the County Asylum. Now, if there is one thing more certain than another about insanity in any particular county, it is that the rate of increase of the certified insane can be predicted with almost unerring accuracy; and we should like to ask the County Council of Lancashire why the required accommodation was not provided. It must be well-nigh ten years since the Borough of Blackburn and the County of Lancashire both decided to build asylums, and yet we have not learnt that either of these was completed. The latter is understood to be a very large one, and had it been opened earlier, or another one built if it be already opened, it is conceivable that the trial and sentence of Pescott might never have been necessary, as the patient would have been in the County Asylum. We should further like to ask what steps are taken by the Crumpsall Workhouse authorities to train their attendants. A very small amount of knowledge is sufficient to convince any nurse that a general paralytic must be tenderly handled, and that humane treatment of the insane is alone permissible in any case."

\section{THE PRINCE OF WALES'S HOSPITAL FUND.}

\section{AN APPEAL.}

OWING to the claims of sufferers from the war, the directors of the Prince of Wales's Hospital Fund suspended their appeal to public support until the present time. The Hon. Secretaries have issued the following letter :-

Bank of England, London, E.C., November 22nd, 1900.

SiR,-Since the outbreak of hostilities in South Africa the executive committee of the Prince of Wales's Hospital Fund have refraind from making any appeal on behalf of the hospitals because of the exceptional claims that have been made upon the public in respect of the War and Famine Funds, but the falling-off in the financial support of the hospitals of London (which is somewhat natural under the circumstances) must be made good if these institutions are to fully continue their useful work.

The executive committee, therefore, appeal to you to assist his Royal Highness the President and the council to make a distribution this year that will materially help to counteract the falling-off that has taken place.

A short statement of the work of this fund is sent herewith, which the executive committee venture to think shows that any moneys entrusted to them will be expended in a manner best calculated to produce the most satisfactory results.

We beg to enclose a subscription form which we earnestly hope you may be willing to fill up for some contribution. It is desirable that further help up to a minimum amount of $£ 25,000$ may be given before December 15 th next. Yours faithfully,

$$
\left.\begin{array}{l}
\text { Duncannon, } \\
\text { J. G. CragGs, }
\end{array}\right\} \text { Honorary Secretaries. }
$$

The latest report of the Hospitals Distribution Committee shows the good work that is done by the fund :fund.

"The past year has been one of increased usefulness of the

"The hospitals concerned have been again visited by subcommittees, consisting of medical men of wide experience and laymen who take special interest in hospital management. These visitations, while they have admirably answered their immediate object of supplying reliable information regarding the merits and needs of the various institutions, have proved of very high value in stimulating improvements, both in construction and in all departments of administration. Defects have been pointed out, and their remedy has been powerfully promoted by making the grants from the fund conditional upon the carrying out of the measures that have been recommended.

"The suggestions made by the visitors have been almost invariably received in a most friendly spirit, and new interest has been often aroused in those more immediately concerned in the several hospitals, leading them to increase their own subscriptions, or to promote in other ways by their individual exertions the needed improvements.

"The importance of the services rendered by the fund has been more generally recognised by the public, so that the sum available for distribution to hospitals this year shows a considerable increase upon last year's amount; the figures being $£ 41,000$ now, as compared with $£ 31,500$ in the previous twelvemonth.

"It is anticipated that the League of Mercy, instituted a year ago by his Royal Highness, will in due time greatly benefit the fund; but the committee can at present only advise the employment of $£ 1,000$ from that source, this being the amount which had been actually paid in when this year's distribution was arranged.

"It is recommended that the additional $£ 9,500$ now at the disposal of the fund be employed partly in the way of donations and partly as annual grants, which are necessary when money is given for the important purpose of opening closed wards, for which continuous maintenance must be provided.

It has been arranged that 45 beds now unoccupied will be brought into use next year; these, added to those thrown open during the last two years, give 287 as the number made available to the poor of the metropolis by the agency of the fund."

Included in last year's list of subscribers and donors were the following annual subscriptions :-

The Prince of Wales, $£ 105$; the Princess of Wales, $£ 25$; Princess Victoria of Wales, $£ 5$; the Duke and Duchess of York, £21; Princes Albert and Edward of York, $£ 2$ 2s.; Princess Victoria of York, $£ 11$ s. ; the Duke and Duchess of Fife, £50; the Duke and Duchess of Teck, £10; Captain Prince Louis of Battenberg, R.N., $£ 11$ s. ; Princess Louis of Battenberg, $£ 11$ s.

In $1897, £ 56,826$; in $1898, £ 32,500$; in 1899 , $£ 42,000$. To keep up this excellent record the fund must be able to rely upon much more assistance than it has received this year.

The cost of management and collection is about $3 \frac{3}{4}$ per cent.

\section{MOSPITAL MEETINGS.}

\section{BRITISH HOME FOR INCURABLES.}

A HALF-YEARLY meeting of the British Home and Hospital for Incurables was held at the Institution, Streatham Common, on Thursday, 15th inst., Colonel Clifford Gascoyne presiding. The chief business to be transacted was the announcement of the result of the recent election, at which five inmates and eleven pensioners were selected; and the secretary having read the names of these, the chairman remarked that since the last meeting the new wing had been completed and opened, and they were now able to accommodate eighty persons-consicierably more than ever before. The customary votes of thanks brought. the proceedings to a close.

\section{THE STORY OF THE INSANE FROM YEAR TO YEAR.}

(THIRTEENTH SERIES.)

\section{CHESHIRE COUNTY ASYLUM AT UPTON.}

ON the last day of the year 1899 this Asylum contained 893 patients. There were 158 first admissions, 44 re-admissions, 86 recoveries, and 105 deaths. Calculated on the year's admissions the recoveries stand at 42.57 per cent., and calculated on the average number resident, the deaths stand at 12.33 per cent., both of these being considerably above the average in kindred institutions. Of the deaths, 45 were caused by cerebral and spinal diseases; 8 by pneumonia; 27 by phthisis ; 3 by pleurisy, and 1 by enteritis. It would tend greatly to the usefulness of this table if the diseases were arranged in groups as is now almost universal in asylums. Of the year's admissions, 29 owed their insanity to moral causes ; 30 to intemperance in drink; 44 to heredi-. 